\title{
MORFOMETRIA DE ÁRVORES NATIVAS DE BERTHOLLETIA EXCELSA BONPL.
}

\author{
Sara Cristina Carvalho de Sousa ${ }^{1}$ \\ Júlio Cesar Wojciechowski² \\ Fabricia Rodrigues da Silva ${ }^{3}$ \\ Anne Francis Agostini Santos ${ }^{3}$
}

\section{INTRODUÇÃO}

Com o decorrer dos anos na Amazônia, poucas espécies obtiveram sucesso no estabelecimento e crescimento em áreas alteradas, devido às interações do ambiente de crescimento com as funcionalidades das espécies, estando sujeitas diretamente a intempéries, ventos fortes, condições de estresses, além de condições microclimáticas adversas (MORAN et al., 2000; SANTOS JR. et al., 2006). As diversas atividades em particular de caráter antropogênico ocasionam uma grande remoção da cobertura vegetal, gerando consequências no sistema solo, vegetação e atmosfera (ASNER et al., 2004).

Dentre as espécies que vem sobrevivendo em áreas alteradas na Amazônia destaca-se a castanheira-do-brasil (Bertholletia excelsa H.B.K.), uma espécie pertencente à família Lecythidaceae, nativa da região Amazônica, que apresenta ampla aceitação no mercado nacional e internacional, principalmente pela qualidade e valor de suas amêndoas (RIBEIRO et al., 1999). Segundo Van Rijsoort et al. (2003) a castanheira-do-brasil é caracterizada como uma planta semidecídua, heliófita, que ocorre em terras firmes do território amazônico.

Conforme a classificação de Koppen, a castanheira concentra-se preferencialmente em locais que apresentam os tipos climáticos Aw ou Am, possui melhor desempenho em áreas onde a precipitação média varia em torno e 1400 a 2800 mm/ano e onde

1 Discente/UNEMAT. Alta Floresta. MT.

2 Profo. Dr. Engenheiro Florestal. UNEMAT.Alta Floresta. MT

3 Profa. MsC. Engenheira Florestal. UNEMAT. Alta Floresta. MT 
ocorre déficit hídrico de dois a cinco meses (CLEMENT, 2000). A temperatura média ideal para seu desenvolvimento pode variar entre 24,3 C e 27,2 C, e em relação à umidade relativa do ar, as variações concentram-se entre 79\% e 86\% (DINIZ e BASTOS, 1974).

Müller et al. (1995) afirmam que as castanheira-do-brasil se desenvolvem melhor em solos argilosos ou argilo-arenosos de textura média a pesada. Pode ser considerada como uma espécie-chave para aliar a conservação ao desenvolvimento devido sua abundancia na região Amazônica, colhida quase que exclusivamente em florestas naturais, é explorada por diversas comunidades em curto prazo e a baixo custo, ocasionando baixo impacto ambiental (ZUIDEMA e BOOT, 2002).

É caracterizada como uma planta social devido a sua frequência em determinados locais estar sempre associada com outras espécies florestais de grande porte. Esses locais de concentração dos castanhais são chamados de reboleiras, aglomerados ou agregados. Podem conter de 50 a 100 indivíduos, cobrindo frequentemente uma área de 5 a 10 hectares, muitas vezes separados por distâncias superiores a $1 \mathrm{~km}$ (COELHO et al., 2005).

Sabe-se que o crescimento das árvores depende de fatores como a disponibilidade dos recursos ambientais (temperatura, precipitação, vento, insolação e nutrientes), espaço físico, edáficos (características físicas, químicas e biológicas), topográficos (inclinação, altitude e exposição), fatores de competição pela influência de outras espécies, tamanho e constituição genética da árvore bem como seu histórico de desenvolvimento, cada um destes fatores podem afetar de forma isolada ou em conjunto seu desenvolvimento (POORTER e BONGERS, 1993).

De acordo com Scoles (2010) a regeneração da castanheira pode ser favorecida por determinadas atividades humanas relacionadas com a abertura do dossel na floresta, e que a coleta de castanha não parece determinante para explicar a baixa densidade de plântulas e juvenis nos castanhais mais envelhecidos, desaconselhando à adoção de medidas restritivas na coleta, recomendando práticas de enriquecimento em áreas propícias para seu crescimento.

Seu caráter longevo e dominante não é incompatível com seu comportamento heliófito durante as primeiras etapas da vida 
(SALOMÃO, 1991), dependendo de clareiras para o crescimento vertical das plântulas germinadas (MORI; PRANCE, 1990).

Estudos experimentais de Tonini (2008) mostram como a castanheira desenvolve-se bem em plantios abertos com alta exposição de luz, mas o seu desempenho cai consideravelmente, quando as condições são de alto sombreamento.

A preservação dos castanhais, principalmente em áreas de expansão da fronteira agrícola, deve ser priorizada no sentido de se manter o germoplasma existente "in situ", com reduzidos custos, proporcionando áreas de refúgios e alimentação para os animais silvestres (CAMARGO, 1997). Segundo Silva et al., (1987) a castanheira é considerada de alta prioridade para conservação da diversidade genética, entre outros fatores por ser uma espécie de gênero monoespecífico.

A castanha é um dos produtos não madeireiros (PFNM) mais importantes da economia florestal da Amazônia. Em termos comerciais, a maior parte das sementes são vendidas para o mercado nacional e internacional, poucas são comercializadas em nível local ou regional (CLEMENT, 2000). Segundo o Instituto Brasileiro de Geografia e Estatística (IBGE, 2010), a castanha é o segundo produto florestal não madeireiro em termos de importância comercial na região Norte do Brasil, perdendo somente para o fruto de açaí (Euterpe).

De acordo com Burger (1939) o conhecimento das relações morfométricas e o acompanhamento da dinâmica das formas de crescimento das árvores tornam-se imprescindível para aprimorar as intervenções silviculturais, principalmente quando se deseja tornar efetiva a utilização de espécies da flora nativa em reflorestamentos com interesses econômicos.

Segundo Orellana e Koehler (2008), o estudo das relações morfométricas de uma espécie florestal fornece os subsídios básicos para estimativas da biomassa de copa, onde variáveis como: altura total da árvore, altura de copa e o diâmetro de copa podem ser correlacionados com a altura total e o diâmetro à altura do peito (DAP).

Segundo Hasenauer (1997), a morfometria de uma árvore e as variáveis derivadas são utilizadas para inferir sobre relações interdimensionais, reconstituir o espaço ocupado por cada árvore, 
a sua estabilidade, vitalidade e produtividade, bem como julgar o grau de concorrência a que cada indivíduo foi ou está sujeito.

A morfometria de espécies arbóreas solitárias permite prever o espaço necessário para cada árvore ao longo de seu desenvolvimento, julgar o grau de concorrência entre indivíduos de um povoamento e fazer inferências sobre a estabilidade e a vitalidade, bem como sobre a produtividade de cada indivíduo (DURLO, 2001).

Durlo e Denardi (1998) propuseram a definição das principais características morfométricas das árvores, como área de projeção de copa, proporção de copa, grau de esbeltez, índice de saliência, índice de abrangência, formal de copa.

A razão entre o comprimento de copa e altura total da copa em porcentagem também é conhecido como a proporção de copa (PC) e indica a fração (\%) que a copa abrange em relação à árvore. Quanto maior a porcentagem de copa, tanto mais vital e produtiva é a árvore (DURLO e DENARDI, 1998).

O índice de saliência (IS) é a relação entre o diâmetro de copa e o DAP e indica quantas vezes o diâmetro de copa é maior que o DAP. Quando se prevê o manejo de um povoamento não pela sua idade, mas pelo diâmetro atingido por seus componentes, pode-se determinar o número máximo de árvores por unidade de área, com o cálculo do índice de saliência, se existir uma correlação significativa com o DAP. Portanto, este índice pode ser usado como indicador de desbaste, determinando, a qualquer tempo, o espaço a ser liberado ao redor de uma árvore selecionada, para que esta cresça sem concorrência (DURLO e DENARDI, 1998).

A razão entre o diâmetro de copa e a altura total da árvore também é conhecida como índice de abrangência (IA). Este índice pode ser considerado para a avaliação do momento de desbaste, caso haja uma alta correlação entre estas variáveis (DURLO e DENARDI, 1998).

O formal de copa (FC) é a relação entre o diâmetro e a altura de copa. Quanto menor o formal de copa, melhor é a produtividade da árvore. Este índice também é utilizado como um critério para a marcação de desbastes (TONINI e ARCO-VERDE, 2005).

O grau de esbeltez (GE) é a relação entre a altura total da árvore e o DAP. Uma relação superior a 1 indica que o crescimento em diâmetro é reduzido em relação à altura (TONINI e ARCO-VERDE, 2005). 
De acordo com Melo et al., (2007) a área da copa é uma das variáveis que merecem todo o destaque entre os parâmetros estruturais, já que é esta variável que controla a entrada de luz, proporciona diferentes nível de umidade do solo e o do ar e principalmente atua como um fator que controla a erosão, já que reduz o impacto direto da chuva no solo. Devido à importância científica, é preciso comparar e avaliar as características morfométricas de árvores nativas de castanheira-do-brasil (Bertholletia excelsa), submetidas à condições distintas de ambiente, como áreas de pastagem e de floresta.

\section{DELINEAMENTO EXPERIMENTAL}

A área de estudo está localizada em uma propriedade rural no município de Alta Floresta no estado de Mato Grosso, cujas medições foram realizadas na Fazenda Mitaju (Figura 1) com aproximadamente uma área de 1000 hectares. Está localizada nas coordenadas geográficas: latitude: -9.828009 e longitude: -55.930262 , a via de acesso é pela rodovia MT 208, a aproximadamente $30 \mathrm{~km}$ do perímetro urbano de Alta Floresta- MT.

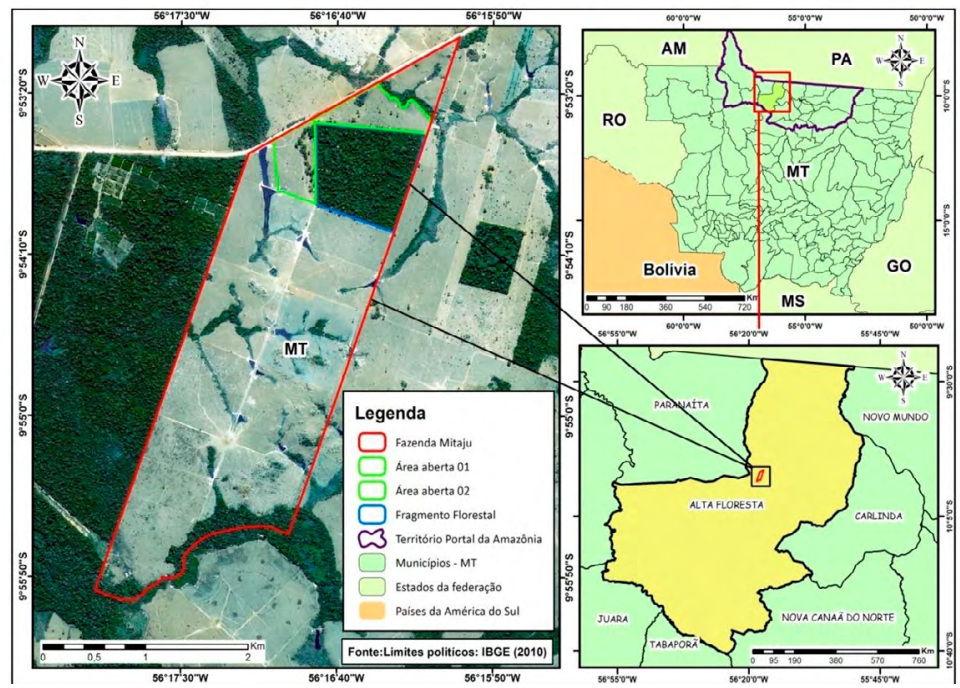

Figura 1. Localização da área de estudo (Fazenda Mitaju). Alta Floresta. MT Fonte: IBGE. 2017. 
O clima da região de acordo com a classificação de Köppen encontra-se no grupo climático Am, característico de clima tropical chuvoso, apresentando uma estação seca bem definida, caracterizado por clima equatorial continental úmido com temperaturas médias anuais de $24,3^{\circ}$ a $24,8^{\circ} \mathrm{C}$, a precipitação pluviométrica na região gira em torno de 2.000 a 2.300 mm, as chuvas são distribuídas em épocas distintas. Geralmente, a estação chuvosa inicia em setembro ou outubro e segue até abril ou maio e o período seco ocorre nos demais meses (ALVARES et al., 2014).

Foram coletados dados morfométricos de 80 indivíduos de castanheira-do-brasil (Bertholletia excelsa), sendo 50 indivíduos avaliados no ambiente de pastagem, e 30 castanheiras no ambiente de floresta nativa. Nas coletas realizadas a campo foram tomadas as coordenadas geográficas de cada indivíduo arbóreo, utilizando um GPS (Global Positioning System) da marca GARMIN que apresenta uma frequência que melhora o posicionamento em áreas de cobertura florestal, além de mensuradas às variáveis: altura total $\left(\mathrm{H}_{\text {total }}\right)$ e altura comercial $\left(\mathrm{H}_{\text {com }}\right)$ utilizando um hipsômetro Blume-Leiss. Com uma trena de 50 metros foram obtidas a circunferência a 1,30 m do solo (CAP) e o diâmetro da copa (DC), medido a partir de quatro raios da copa nas direções norte $(0 \circ)$, sul (180), leste (90) e oeste $\left(270^{\circ}\right)$, e tomando-se como ponto de origem o centro do tronco e distanciando-se até o limite da copa, de acordo com a Figura 2, conforme método adaptado de ROMAN et al., (2009).
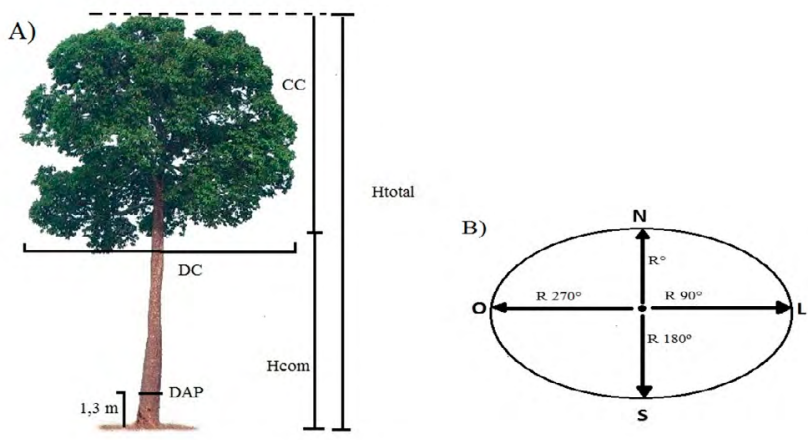

Figura 2. A) Modelo de uma árvore e suas características dimensionais, adaptado de BURGER (1939), DURLO e DENARDI (1998) e ROMAN et al., (2009); B) Esquema de medição do diâmetro de copa 
Onde: Comprimento de copa (CC); Altura total (Htotal); Altura comercial (Hcom); Diâmetro de copa (DC); Diâmetro a altura do peito (DAP).

A partir destas variáveis levantadas a campo, foi possível realizar a análise das seguintes relações morfométricas (Tabela 1)

\begin{tabular}{cc}
\hline Índice & Formulação \\
\hline CC & $\mathrm{H}_{\text {total }}-\mathrm{H}_{\text {com }}$ \\
DC & {$[(\mathrm{N}+\mathrm{S})+(\mathrm{L}+\mathrm{O})] / 2$} \\
PC & $\left(\mathrm{CC} / \mathrm{H}_{\text {total }}\right) * 100$ \\
GE & $\mathrm{H}_{\text {total }} / \mathrm{DAP}$ \\
FC & $\mathrm{DC} / \mathrm{CC}$ \\
IA & $\mathrm{DC} / \mathrm{H}_{\text {total }}$ \\
IS & $\mathrm{DC} / \mathrm{DAP}$ \\
AC & $\left.\left(\pi^{*} \mathrm{DC}\right)^{2}\right) / 4$ \\
\hline
\end{tabular}

Tabela 1 - Variáveis morfométricas analisadas.

Onde: Comprimento da Copa (CC); Diâmetro da Copa (DC) nas direções norte (N $=0 \circ)$, sul $\left(S=180^{\circ}\right)$, leste $\left(L=90^{\circ}\right)$ e oeste $\left(O=270^{\circ}\right)$; Proporção da Copa $(P C)$; Grau de Esbeltez (GE); Formal de Copa (FC); Índice de Abrangência (IA); Índice de Saliência (IS) e Área de Copa (AC).

A análise estatística e exploratória dos dados apresentou a seguinte ordem: análise visual para verificação do comportamento geral dos dados utilizando os histogramas de frequência, teste de normalidade de Shapiro-Wilk, teste de homogeneidade das variâncias de Levene, em seguida teste comparação de médias " $\mathrm{t}$ " de Student, finalizando com a tabela com o resumo dos índices morfométricos por ambiente.

A estatística "W" do teste de Shapiro-Wilk foi calculada mediante a equação 1:

Equação 1:

$$
W=\frac{\left(\sum_{i=1}^{n} a_{i} x_{(i)}\right)^{2}}{\sum_{i=1}^{n}\left(x_{i}-\bar{x}\right)^{2}}
$$

Em que os $x_{(i)^{\prime} \text { s }}$ são os valores amostrais ordenado e os $a_{(i)^{\prime} \text { s }}$ são constantes geradas das médias, variâncias e covariâncias das 
estatísticas de ordem de uma amostra aleatória de tamanho $\mathrm{n}$ de uma distribuição normal.

Caso o valor observado (valor-p) do teste, for menor que o nível de significância $(=5 \%)$, rejeita-se a hipótese nula $\left(H_{0}\right)$, devido os dados não seguirem a hipótese de normalidade. $\mathrm{E}$ se o valor observado (valor-p) estiver acima do nível de significância (= 5\%) não se rejeita $\circ \mathrm{H}_{0}$, devido os dados seguirem a hipótese de normalidade.

O teste de Levene, foi realizado com o propósito de verificar a homogeneidade de variâncias, e ainda adequar o teste " $\mathrm{t}$ " ao tipo de para a variância dos dados, otimizando os graus de liberdade. Seguindo o resultado do teste de Levene, foi realizado o teste " $\mathrm{t}$ " de Student mediante a equação 2.

Equação 2:

$$
t=\frac{\text { média } a_{1}-\text { média }}{\text { erro padrão }}
$$

Onde: $\mathrm{t}=$ estatística do teste; média $_{1}=$ média dos valores amostrados no ambiente clareira; média $_{2}=$ média dos valores amostrados no ambiente floresta; erro padrão = erro padrão da estimativa dos dados.

O teste " $\mathrm{t}$ " foi aplicado com o intuito de comparar estatisticamente as diferenças encontradas em relação às médias dos indivíduos nos dois ambientes.

O teste resulta em dois valores principais a observar. A estatística do teste e o valor de " $p$ " que é a confiabilidade do teste ligado à hipótese nula $(\alpha)$. Quando encontramos um " $p$ " valor menor que o nível de significância adotado (= 5\%), rejeita-se a hipótese nula $\left(\mathrm{H}_{0}:_{1}={ }_{2}\right)$, de que as médias entre os dois ambientes são de fato estatisticamente iguais.

Todas as análises estatísticas e exploratórias aplicada aos dados coletados no estudo foram construídas utilizando-se os recursos do pacote Basic, instalados a partir do programa computacional R Core Team (2016). 


\section{RESULTADOS E DISCUSSÃO}

\section{Análise exploratória das variáveis morfométricas}

Podemos observar em relação ao comportamento geral dos dados demonstrados nos histogramas de frequência (Figura 3), que os mesmos tiveram uma distribuição regular em todas as classes analisadas, com uma tendência da maioria das variáveis a uma distribuição relativamente normal, a maioria dos indivíduos amostrados apresentou um comprimento de copa (CC) em torno de 10 metros, o diâmetro de copa (DC) dos indivíduos se concentrou na classe de 20 a 25 metros, o maior diâmetro chegou a 50 metros.

A maioria das castanheiras-do-brasil amostradas apresentou aproximadamente $35 \%$ de proporção de copa. A maior frequência do grau de esbeltez se concentrou entre as classes de 0,15 a 0,20. O formal de copa médio foi em torno de 2 . O índice de abrangência médio que os indivíduos apresentaram foi de 0,6 e o máximo foi de 1,5. A maior frequência dos indivíduos relacionada ao índice de saliência se concentrou na classe de 0,10 a 0,20. A maioria dos indivíduos apresentou uma área de copa de $250 \mathrm{~m}^{2}$. Os histogramas gerais nos permitem avaliar o comportamento dos dados e suas maiores frequências.

O teste "W" de Shapiro-Wilk resultou em aderência a distribuição normal para todos os índices testados.

Para comparações independentes, existe uma pressuposição básica para garantir que o teste " $\mathrm{t}$ " seja exato, essa pressuposição refere-se à homocedasticidade das variâncias (SNEDECOR e COCHRAN, 1980). De acordo com Levene (1960) o teste de comparação de variâncias (Levene) tem se constituído como uma técnica muito útil para a comparação de variâncias quando as suposições básicas não são satisfeitas.

Em relação ao teste de Levene, este resultou em variâncias homogêneas para os índices: comprimento de copa (CC) e proporção de copa (PC), enquanto que os índices: grau de esbeltez (GE), formal de copa (FC), índice de abrangência (IA), diâmetro de copa (DC), índice de abrangência (IA), índice de saliência (IS), área de copa (AC) obtiveram variâncias heterogêneas. 

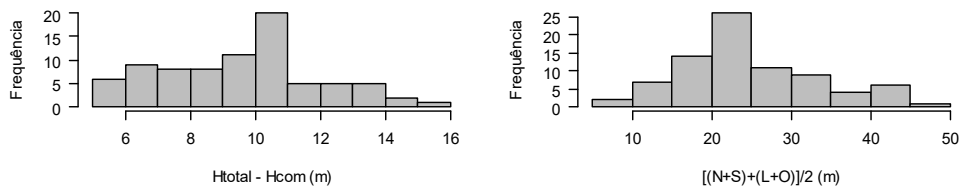

Proporção de Copa

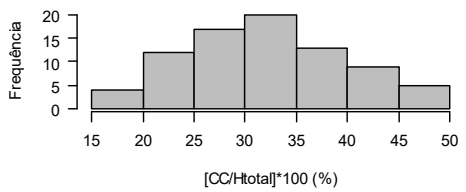

Grau de Esbeltez

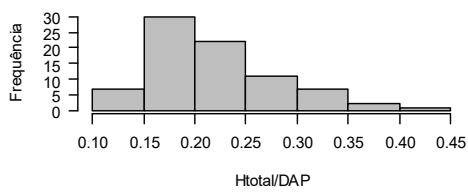

Formal de Copa

Índice de Abrangência
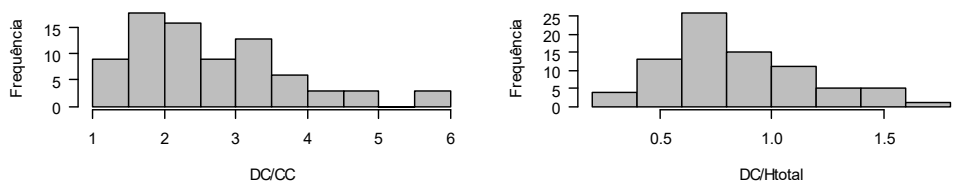

Índice de Saliência

Área de Copa
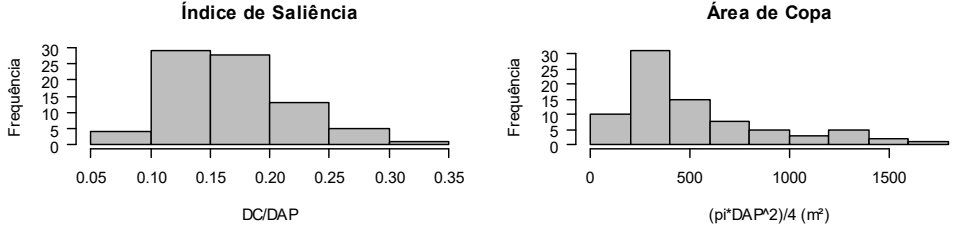

Figura 3. Histogramas de frequência dos índices morfométricos calculados da espécie Bertholletia excelsa nos ambientes pastagem e floresta

Fonte: Construção dos Autores.

A partir do resultado do teste de homogeneidade de variâncias (Teste de Levene), foi possível definir qual o teste " $\mathrm{t}$ " adequado para realizar a comparação das médias, entre os ambientes, sendo possível ajustar melhor os graus de liberdade a variâncias dos dados (Tabela 2).

\begin{tabular}{ccc}
\hline Índices & Valor de $\boldsymbol{t}$ & Valor de $\boldsymbol{p}$ \\
\hline CC & 0.7572 & $0.4512^{*}$ \\
DC & 7.0359 & $<0,001^{* *}$ \\
PC & 1.9246 & $0.0579^{\text {ns }}$ \\
GE & 4.7085 & $<0,001^{* *}$ \\
& & Continua...
\end{tabular}




$\begin{array}{lll}\text { FC } & 5.2365 & <0,001^{* *} \\ \text { IA } & 7.8366 & <0,001^{* *} \\ \text { IS } & 4.7701 & <0,001^{* *} \\ \text { AC } & 6.6242 & <0,001^{* *}\end{array}$

Tabela 2 - Teste " $\mathrm{t}$ " de Student, comparação de médias entre os ambientes pastagem e floresta para os índices morfométricos

Fonte: Construção dos autores.

Onde: ${ }^{*} ; *$ significativo a 5 e $1 \%$ respectivamente (médias encontradas no ambiente pastagem e floresta são estatisticamente diferentes); ns - não significativo.

De acordo com o Teste " $\mathrm{t}$ " de Student, todos os índices com exceção do índice proporção de copa (PC) foram diferentes estatisticamente. A diferenciação constatada nos ambientes, provavelmente ocorreu a partir do ano de 1999, observada a partir de uma séria histórica de imagens de satélite que compõe a plataforma do Google Earth Pro. A qual evidencia a retirada da vegetação na área de pastagem, que anterior a está data era constituído de um ambiente de floresta nativa.

\section{Características morfométricas}

Os valores médios, mínimos, máximos, 1 o quartil, mediana, 3ㅇ quartil e o coeficiente de variação (CV), variáveis dendrométricas e morfométricas da castanheira-do-brasil, nos ambientes pastagem e floresta encontram-se nas Tabelas 3 e 4, respectivamente.

As alturas totais $\left(\mathrm{H}_{\text {total }}\right)$ mínimas foram de 16,20 metros na pastagem e 22,60 metros na floresta, sendo a máxima de 36,80 na pastagem e 37,30 metros na floresta, vale ressaltar que ocorre uma maior variação da altura total no ambiente pastagem em relação à floresta.

A altura comercial $\left(\mathrm{H}_{\text {com }}\right)$ do fuste, definida também como a altura de inserção da copa, apresentou uma variação no ambiente pastagem entre 9,60 a 27,60 metros, sendo a média de 19,63 metros, e coeficiente de variação (CV) de $12 \%$. A altura comercial no ambiente floresta diferenciou-se de 12,5 a 26,70 metros com a média de 21,93 metros e $15 \%$ de variação dos dados. 


\begin{tabular}{|c|c|c|c|c|c|c|c|c|c|c|c|}
\hline Medidas & $\begin{array}{l}\mathrm{H}_{\text {total }} \\
(\mathrm{m})\end{array}$ & $\begin{array}{l}\mathrm{H}_{\text {com }} \\
(\mathrm{m})\end{array}$ & $\begin{array}{l}\text { DAP } \\
(\mathrm{cm})\end{array}$ & $\begin{array}{c}\mathrm{CC} \\
(\mathrm{m})\end{array}$ & $\begin{array}{c}\text { DC } \\
(\mathrm{m})\end{array}$ & $\begin{array}{l}P C \\
(\%)\end{array}$ & GE & FC & IA & IS & $\begin{array}{l}\mathrm{AC} \\
\left(\mathrm{m}^{2}\right)\end{array}$ \\
\hline Mínimo & 16,20 & 9,60 & 62,39 & 5,50 & 17,21 & 18,46 & 0,10 & 1,43 & 0,56 & 0,12 & 232,6 \\
\hline $1^{\circ}$ quartil & 27,70 & 17,35 & 136,90 & 7,65 & 21,70 & 27,31 & 0,17 & 2,22 & 0,74 & 0,15 & 369,5 \\
\hline Mediana & 29,75 & 20,05 & 154,10 & 9,84 & 27,12 & 33,39 & 0,19 & 3,03 & 0,95 & 0,18 & 577,5 \\
\hline Média & 29,37 & 19,63 & 154,80 & 9,75 & 28,92 & 33,35 & 0,20 & 3,14 & 0,99 & 0,19 & 706,2 \\
\hline $3^{\circ}$ quartil & 31,15 & 21,30 & 171,90 & 11,36 & 34,80 & 39,60 & 0,22 & 3,85 & 1,18 & 0,23 & 950,9 \\
\hline Máximo & 36,80 & 27,80 & 257,50 & 14,85 & 46,79 & 47,77 & 0,32 & 5,97 & 1,64 & 0,341 & 1719,0 \\
\hline CV(\%) & 12,0 & 18,0 & 22,0 & 25,0 & 28,0 & 23,0 & 22,0 & 36,0 & 29,0 & 27,0 & 56,0 \\
\hline
\end{tabular}

Tabela 3 - Variáveis dendrométricas $\left(\mathrm{H}_{\text {total }}, \mathrm{H}_{\text {com }}\right.$ e DAP) e morfométricas (CC, DC, PC, GE, FC, IA, IS e AC) pertencentes ao ambiente pastagem

Fonte: Construção dos autores.

$\mathrm{H}_{\text {total }}=$ Altura total, $\mathrm{H}_{\text {com }}=$ Altura comercial, DAP = Diâmetro à altura do peito, CC = Comprimento de Copa, $\mathrm{DC}=$ Diâmetro de Copa, $\mathrm{PC}=$ Proporção de Copa, $\mathrm{GE}=$ Grau de Esbeltez, FC = Formal de Copa, IA = Índice de Abrangência, IS = Índice de Saliência, AC = Área de Copa.

\begin{tabular}{lccccccccccc}
\hline Medidas & $\begin{array}{c}\mathrm{H}_{\text {total }}(\mathrm{m}) \\
(\mathrm{H})\end{array}$ & $\begin{array}{c}\mathrm{H}_{\text {com }} \\
(\mathrm{m})\end{array}$ & $\begin{array}{c}\mathrm{DAP} \\
(\mathrm{cm})\end{array}$ & $\begin{array}{c}\mathrm{CC} \\
(\mathrm{m})\end{array}$ & $\begin{array}{c}\mathrm{DC} \\
(\mathrm{m})\end{array}$ & $\begin{array}{c}\mathrm{PC} \\
(\%)\end{array}$ & GE & FC & IA & $\begin{array}{c}\text { IS } \\
\begin{array}{c}\mathrm{AC} \\
\left(\mathrm{m}^{2}\right)\end{array}\end{array}$ \\
\hline Mínimo & 22,60 & 12,50 & 52,13 & 5,70 & 8,59 & 18,06 & 0,18 & 1,11 & 0,29 & 0,09 & 57,89 \\
$1^{\circ}$ quartil & 28,60 & 21,02 & 95,41 & 7,69 & 14,30 & 25,91 & 0,20 & 1,50 & 0,51 & 0,13 & 160,50 \\
Mediana & 31,60 & 22,60 & 117,80 & 9,83 & 19,76 & 30,06 & 0,25 & 1,91 & 0,60 & 0,14 & 306,60 \\
Média & 31,26 & 21,93 & 123,70 & 9,34 & 18,47 & 29,99 & 0,26 & 2,06 & 0,59 & 0,15 & 288,90 \\
$3^{\circ}$ quartil & 33,33 & 24,20 & 149,60 & 10,52 & 21,58 & 34,25 & 0,30 & 2,46 & 0,64 & 0,17 & 365,70 \\
Máximo & 37,30 & 26,70 & 212,60 & 15,76 & 30,75 & 48,26 & 0,43 & 3,68 & 1,04 & 0,21 & 742,60 \\
CV(\%) & 10,5 & 15,0 & 33,0 & 25,0 & 28,0 & 24,0 & 25,0 & 34,0 & 29,0 & 21,0 & 53,0 \\
\hline
\end{tabular}

Tabela 4 - Variáveis dendrométricas $\left(\mathrm{H}_{\text {total }}, \mathrm{H}_{\text {com }}\right.$ e DAP) e morfométricas (CC, DC, PC, GE, FC, IA, IS e AC) pertencentes ao ambiente floresta

Fonte: Construção dos Autores.

$\mathrm{H}_{\text {total }}=$ Altura total, $\mathrm{H}_{\text {com }}=$ Altura comercial, DAP = Diâmetro à altura do peito, $\mathrm{CC}$ = Comprimento de Copa, $\mathrm{DC}=$ Diâmetro de Copa, $\mathrm{PC}=$ Proporção de Copa, $\mathrm{GE}=$ Grau de Esbeltez, FC = Formal de Copa, IA = Índice de Abrangência, IS = Índice de Saliência, AC = Área de Copa.

O DAP entre os ambientes analisados apresentou uma média de 154,8 e $123,7 \mathrm{~cm}$ nos ambientes de pastagem e floresta respectivamente. Um dos fatores que pode ocasionar o menor DAP dos indivíduos que estão situados na floresta é a competição entre árvores por luz, água e nutrientes, já que a maior disponibilidade de espaço vital propicia mais o desenvolvimento do diâmetro nas 
partes baixas das árvores do que nas partes mais elevadas. Maior crescimento em diâmetro em espaços vitais maiores foi constatado por Leite et al., (2006) em plantio de Pinus taeda nas idades entre 4 e 14 anos.

Os valores do comprimento de copa (CC) médios foram de 9,75 e 9,34 nos ambientes pastagem e floresta respectivamente, em ambos ambientes essa variável apresentou o CV de $25 \%$.

O diâmetro de copa (DC) é uma variável básica para a dedução de outras características das árvores e corresponde à distância entre as linhas de projeção dos pontos mais externos da copa. Esta variável se movimentou em uma grande faixa de variação em relação à média nos dois ambientes sendo de 28,92 e 8,47 nos ambientes pastagem e floresta respectivamente.

A proporção de copa (PC) ou porcentagem de copa corresponde à relação entre o comprimento da copa e altura total da árvore. Esta variável (juntamente com características qualitativas da copa) é um indicador da vitalidade das árvores. A espécie castanheira-do-brasil, nos dois ambientes obteve a proporção de copa média entre 29,9 a 33,5\%, ou seja, seu fuste representou a maior parte de sua morfometria (aproximadamente 65\%) em relação à copa. Orellana e Koehler (2008) em estudo com Ocotea odorífera encontraram proporção média de copa de 55,2\% e Durlo e Dernardi (1998) encontraram valor de proporção de copa médio de 49,2\% para a canjerana.

O grau de esbeltez (GE) médio dos indivíduos foi de 0,20 no ambiente pastagem e 0,26 no ambiente floresta. Segundo Costa et al., (2009), quanto maior o grau de esbeltez maior a instabilidade da árvore, ficando suscetível a quebra do fuste e copa em detrimento de ventos fortes. Sendo assim as castanheira-do-brasil, amostradas apresentaram uma boa estabilidade segundo o grau de esbeltez (GE).

Segundo Durlo e Denardi (1998), o formal de copa (FC), se denomina a relação entre o diâmetro de copa e a altura da mesma. Se considerarmos uma mesma espécie e sítio, quanto menor o formal de copa, mais produtiva será a árvore. Neste estudo as castanheiras apresentaram um formal de copa 3,14 e 2,06 na pastagem e floresta respectivamente. Mattos (2007) obteve valor médio igual a 0,63 para essa variável em estudo com louros nativos, 
no interior de fragmentos de floresta secundária no Rio Grande do Sul. Durlo e Denardi (1998) obtiveram formal de copa médio de 0,74 para Cabralea canjerana, também em floresta secundária no Rio Grande do Sul.

O índice de abrangência (IA) é uma variável calculada pela relação entre o diâmetro de copa e a altura total da árvore. O índice de abrangência médio dos indivíduos foi de 0,99 e 0,59 nos ambientes de pastagem e floresta. Zanon (2007) observou uma variação do índice de abrangência entre 0,20 até 0,58 para a araucária. Mattos (2007) encontrou um índice de abrangência médio de 0,26 para Cordia trichotoma em floresta nativa no Rio Grande do Sul.

Segundo Dawkins (1963), espécies que apresentam valores de índice de saliência (IS) maiores do que 25 caracterizam espécies de baixo crescimento. Neste estudo, a razão DC e DAP (IS) obtiveram uma variação da média de 0,19 na pastagem 0,15 na floresta, caracterizando assim uma espécie de alto crescimento. Tonini e Arco-Verde (2005) encontraram valores médios de índice de saliência para a castanheira-do-brasil (Bertholletia excelsa) de 50; para a andiroba (Carapa guianensis) de 14,7; para o ipê-roxo (Tabebuia avellanedae) de 32,3 e para o jatobá (Hymenaea courbaril) de 33,1.

A área de copa (AC) é uma medida que cobre toda a superfície de copa de uma árvore. De acordo com Mitscherlich (1978) a partir da mensuração desta variável é possível conhecer o espaço ocupado por uma árvore. A área de copa dos indivíduos amostrados foi constatada como o índice que apresentaram a maior variação dos dados em relação à média sendo de 706, $2 \mathrm{~m}^{2}$ no ambiente clareira e $288,90 \mathrm{~m}^{2}$ no ambiente floresta.

\section{CONSIDERAÇÕES FINAIS}

A morfometria da castanheira está sujeita a mudanças de acordo com o seu desenvolvimento e ambiente. Os índices comprimento de copa (CC), diâmetro de copa (DC), proporção de copa (PC), formal de copa (FC), índice de abrangência (IA), índice de saliência (IS), área de copa (AC), foram maiores no ambiente de pastagem. Em relação ao grau de esbeltez (GE) os indivíduos pertencentes ao ambiente floresta apresentaram melhor estabilidade dimensional em relação aos indivíduos em áreas abertas. 


\section{REFERÊNCIA}

ASNER, G. P.; ELMORE, A. J.; OLANDER, L. P.; MARTIN, R. E.; HARRIS, A. T. Grazing systems, ecosystem responses, and global change. Annual Review of Environment and Resources, v. 29, p. 261-299, 2014.

ALVARES, C. A.; STAPE, J. L.; SENTELHAS, P. C.; GONÇALVES, J. L. M.; Köppen ıs climate classification map for Brazil. Meteorologische Zeitschrift, Stuttgart, v. 22, n. 6, p. 711-728, 2014.

BURGER, H. Baum krone und zuwachs in zweihi ebsreifenfichten beständen. Mitteilungen der Schweizerischen. Ans taltfür das ForstlicheVersuchswesen, v.21, p.147-176, 1939.

CAMARGO, I. P. Estudos sobre a propagação da Castanheira-do-Brasil. 127 p. Tese (Doutorado em Fitotecnia) Universidade Federal de Lavras. Lavras, 1997.

CLEMENT, C. R. Castanha-do-pará (Bertholletia excelsa). In: CLAY, J. W.; SAMPAIO, P. T. B.; CLEMENT, C. R. Biodiversidade Amazônica: exemplos e estratégias de utilização. Manaus: INPA Programa de Desenvolvimento Empresarial e Tecnológico, 119-131p, 2000.

COELHO, M. F. B.; SANTOS, G.M. dos; ALVES, H.S.; TANNURI, A. M.; VELASCO, L. N.; SONOHATA, M. M.; PERES, J. M. de S.; PEIXOTO, F. B.; MUNIZ, C. A. S. PROGRAMA INTEGRADO DA CASTANHA (PIC): Coleta e comercialização da Castanha-do-Brasil pelos Rikbaktsa e Zoró. Cuiabá-MT: FAMEV/UFMT, 63p. (Primeiro Relatório Produtos), 2005.

COSTA, J. R.; CASTRO, A. B. C.; WANDELLI, E. V.; CORAL, S. C. T.; SOUZA, S. A. G. Aspectos silviculturais da castanha-do-brasil (Bertholletia excelsa) em sistemas agroflorestais na Amazônia Central. Acta Amazônica, v. 39, n. 4, p. 843-850, 2009.

DAWKINS, H. C. Crow diameters: their relation to bole diameter in tropical Forest trees. Commonw. Forest Review, v. 42, n. 4, p. 318-333, 1963.

DINIZ, T. D. A. S.; BASTOS, T. X. Contribuição ao clima típico da castanha-do-brasil. Boletim Técnico do IPEAN, n. 64, p. 59-71, Belém, 1974.

DURLO, M. A. Relações morfométricas para Cabralea canjerana (Well.) Mart. Santa Maria, Ciência Florestal, v.11, p. 141-150, jun. 2001.

DURLO, M.A.; DENARDI, L. Morfometria de Cabralea canjerana, em mata secundária nativa do Rio Grande do Sul. Ciência Florestal, v.8, p.55-56, 1998.

DURLO, M. A; DENARDI, L. Morfometria de Ocotea odorífera em mata secundária nativa do Rio Grande do Sul. Santa Maria, Ciência Florestal, v. 8, 1998.

HASENAUER, H. Dimensional relationships of open-grown trees in Austria. Forest Ecology and Management, v.96, p.197-206, 1997.

INSTITUTO BRASILEIRO DE GEOGRAFIA E ESTATÍ́STICA (IBGE), 2010. Produção da extração vegetal e silvicultura 2009: v. 23: 1-45. IBGE, Rio de Janeiro. 
LEITE, H. G.; NOGUEIRA, G.S.; MOREIRA, A.M. Efeito do espaçamento e da idade sobre variáveis de povoamentos de Pinus taeda L. Viçosa, 4.ed. Revista Árvore, p.603-613, 2006.

LEVENE, H. Robust Test for Equality of Variances, Stanford University Press, California, United States p. 278-292. 1960.

MATTOS, R. B. Produtividade e incremento de Cabralea canjerana (Vell.) Mart., Cedrela fissilis Vell. e Cordia trichotoma (Vell.) Arrab. Ex Steud., em floresta nativa no Rio Grande do Sul. Santa Maria. 105 f. Tese (Doutorado em Engenharia Florestal) - Universidade Federal de Santa Maria, 2007.

MELO, A. C. G.; MIRANDA, D. L. C.; DURIGAN, G. Cobertura de copas como indicador de desenvolvimento estrutural de reflorestamentos de restauração de matas ciliares no médio vale do Paranapanema, SP, Brasil. Viçosa, 2.ed. Revista Árvore, .321-328, 2007.

MITSCHERLICH, G. Wald, Wachstum und Umwelt. Eine Einführung in die ökologischen Grundlagen des Waldwachstums. Erster Band: Form und Wachstum von Baum und Bestand. II Auflage. J, D. Sauerländer's Verlag. Frankfurt am Main. 144 p. 1987.

MORAN, E. F.; FALESI, I. Effects of soil fertility and land-use on forest sucession in Amazonia. Forest Ecology and Management, Amsterdam, v. 139, n. 1-3, p. 93-108, 2000.

MORI, S. A.; PRANCE, G. T.; BALICK, M.J. Taxonomy, ecology and economic botany of the Brazil nut (Bertholletia excelsa Humb. e Bonpl.: Lecythidaceae). New York, Advances in Economic Botany. v. 8, p.130-150, 1990.

MÜLLER, C. H. et al. Castanha-do-Brasil. Brasília: EMBRAPA, 1995.

ORELLANA, E.; KOEHLER, A. B. Relações morfométricas de Ocotea odorífera (Vell). Rohwer. Curitiba, 2.ed. Revista Acadêmica Ciências Agrárias e Ambientais, v. 6, p. 229-237, 2008.

POORTER, L.; BONGERS, F. Ecology of tropical forests. Wageningen: Agricultural University, p.223 1993.

RIBEIRO, J. E. L. et al. Flora da reserva Duke: guia de identificação das plantas vasculares de uma floresta de terra-firma na Amazônia Central. Manuas: INPA, 816 . 1999.

R CORE TEAM. R: A language and environment for statistical computing. $R$ Foundation for Statistical Computing, Vienna, Austria: R Foundation for Statistical Computing, 2016. Disponível em:<http://www.R-project.org/>. Acesso em: 20 nov. 2016.

ROMAN, M.; BRESSAN, D. A.; DURLO, M. A. Variáveis morfométricas e relações Interdimensionais para Cordia trichotoma (Vell.) Arráb. Ex Steud. Ciência Florestal, v.19, p. 473-480, 2009. 
SALOMÃO, R. P. Estrutura e densidade de Bertholletia excelsa H. e B. ("Castanheiro") nas regiões de Carajás e Marabá, Estado do Pará. Boletim do Museu Paraense Emílio Goeldi, série Botânica, Belém, v.7. p.47-68, 1991.

SANTOS JUNIOR, U. M.; GONCALVES, J. F. C.; FELDPAUSCH, T. R. Growth, leaf nutrient concetration and photo synthetic nutrient use efficiency in tropical tree species planted in degraded areas in Central Amazonia. Forest Ecology and Management, Amsterdam, v. 226, n. 1-3, p. 299-309, 2006.

SCOLES, R. Efeito da intensidade de coleta de castanhas na regeneração e demografia de Bertholletia excelsa: subsídios para o manejo dos castanhais nativos. Manaus, Congresso Nacional de Botânica, 2010.

SILVA, M. F. F.; ROSA, N. A.; OLIVEIRA, J. Estudos botânicos na área do Projeto Ferro Carajás. 5 - Aspectos florísticos da mata do Rio Gelado, Pará. Boletim do Museu Paraense Emílio Goeldi, série Botânica p. 20, 1987.

SNEDECOR, G. W.; COCHRAN, W. G. Statistical methods. 7. ed. Ames: The lowa State University, 507 p. 1980.

TONINI, H. Relation ship of Brazil nut seed yield to crown morphometric characteristics and competition indexes. Pesquisa Agropecuária Brasileira, Brasília, p.1509-1516, 2008.

TONINI, H.; ARCO-VERDE M. F. Morfologia da copa para avaliar o espaço vital de quatro espécies nativas da Amazônia. Pesquisa Agropecuária Brasileira, Brasília, v. 40, n. 7, p. 633-638, 2005.

VAN RIJSOORT, J; UGUETO, S.; ZUIDEMA, P. Almendro (Bertholletia excelsa): Estructura de poblacione nun bosque tropical y crecimiento de plântulas en diferentes intensidades de luz. In: POORTER, L. (Ed.). Investigaciones ecológicas, forestales y socioeconômicas em el norte de la Amazônia Boliviana. Riberalta: PROMAB, p. 23-27, 2003.

ZANON, M. L. B. Crescimento da Araucaria angustifolia (Bertol.) Kuntze diferenciado por dioicia. $110 \mathrm{f}$. Tese (Doutorado em manejo florestal). Universidade Federal de Santa Maria. Santa. Santa Maria, 2007.

ZUIDEMA, P. A.; BOOT, R. G. A. Demography of the Brazil nut tree (Bertholletia excelsa) in the Bolivian Amazon: impact of seed extraction recruitment and population dynamics. Journal of Tropical Ecology, Cambridge. p. 31, 2002. 